\title{
A PRÁTICA DO DESENHO COMO INSTRUMENTO DE ANÁLISE DAS OBRAS DE ARTE
}

\author{
Arthur Gomes Valle ${ }^{1}$
}

1. A presente comunicação tem como objetivo principal defender a idéia de que a prática do desenho é um instrumento de análise útil para o pesquisador de artes plásticas, na medida em que facilita a tomada de consciência e permite a representação concreta dos fatores formais responsáveis pela transmissão do significado e do caráter expressivo de uma obra de arte. Fruto de uma pesquisa ainda em andamento, o texto aqui apresentado não tem a pretensão de esgotar seu tema, mas antes apresentar, de maneira um tanto assistemática, exemplos dessa postura analítica que envolve uma espécie de "recriação" de seu objeto de estudo e que pode permitir com isso o acesso a níveis de significação normalmente ignorados por outros métodos de análise das obras de arte.

Dentro da pedagogia artística tradicional, a prática da realização de cópias é talvez a que mais mantêm afinidades com os métodos que serão aqui abordados. Uma das funções da cópia, prática difundida nas mais diversas culturas artísticas, é possibilitar a assimilação por parte de quem a realiza da maneira como uma obra incorpora nas suas próprias configurações os seus conteúdos expressivos específicos. No que aqui nos toca mais de perto, é possível observar que também historiadores e teóricos se valeram de procedimentos semelhantes em seus trabalhos.

Por exemplo, nos meios intelectuais de língua alemã, a partir de finais do século XIX, é mesmo possível encontrar certas convergências entre uma valorização da prática do desenho e a busca de novas abordagens metodológicas para a história da arte. Podendo em certa medida ser vinculada àquela tendência à "pura visibilidade" que nascera no círculo formado pelo filósofo Konrad Fiedler, pelo pintor Hans von Marées e pelo escultor Hildebrandt, tal desejo de renovação metodológica assumiu por vezes tons eminentemente polêmicos. Em seu ensaio-manifesto Rumo a um estudo rigoroso da arte, de 1931, Hans Sedlmayr, historiador austríaco pertencente à segunda geração da chamada Escola de Viena, criticava a minúcia empírica da história da arte e apontava os limites de seus meios de análise costumeiros - atribuição, filologia, iconografia, mecenato e história social; para Sedlmayr, a maioria dos estudos levados a cabo até então, apesar de seu valor, não proporcionavam um conhecimento genuíno das obras de arte naquilo que tinham de específico. Parafraseando o psicólogo gestaltista Max Wertheimer, Sedlmayr descrevia com as seguites palavras o seu desencanto:

\footnotetext{
você vem a procura de algo sólido, vívido, que o tocou profundamente, procura os estudos a seu respeito, você lê e lê (ou começa o tipo costumeiro de pesquisa), e, no final das contas, você tem a nítida impressão de que acumulou bastante coisa, mas que isso simplesmente em nada resulta. De alguma maneira, aquilo que parecia o mais importante e o mais essencial - o coração mesmo do problema - foi perdido no processo". [1]
}

Em seu artigo, Sedlmyar esboçava em contrapartida à história da arte usual, baseada no estudo documental do que ele qualificava como "cadáveres artísticos", uma "segunda" história da arte que finalmente faria justiça às intenções propriamente estéticas presentes no cerne de seus objetos de estudo.

\footnotetext{
${ }^{1}$ Doutorando em História e Crítica da Artes pelo Programa de Pós -Graduação em Artes Visuais da Escola de Belas Artes / Universidade Federal do rio de Janeiro (PPGAV - EBA/UFRJ).
} 
Mais diretamente relacionada ao nosso tema, outra figura do cenário artístico alemão de inícios do século XX que sustentou uma polêmica semelhante foi Johannes Itten, o famoso pintor e pedagogo, uma das principais figuras dos anos iniciais da Bauhaus de Weimar, onde lecionou entre 1919 e 1923. Em um de seus diários, Itten descreve o historiador de arte em termos análogos aos de Sedlmayr como uma figura desoladora, "um profeta voltado para o passado, encarregado de interpretar fenômenos vulcânicos enquanto sedimentos"[2]. Essa concepção de Itten era parcialmente semelhante àquela de outro famoso pintor moderno, Wassily Kandinsky, que, argumentando a partir da sua crítica do materialismo oitocentista, pregava uma renovação decisiva da história da arte que seria marcada essencialmente por uma abordagem intuitiva de seus objetos de estudo, capaz de revelar como uma forma exprime o seu “conteúdo interior" [3].

Certamente, as opiniões acima reproduzidas tem uma intenção deliberadamente polêmica e apenas em parte fazem jus ao pensamento freqüentemente mais nuançado de seus autores. Se as citamos é porque exprimem com veemência uma inquietação para a qual cremos ser sensato não fechar os ouvidos: à uma postura analítica que encara uma determinada obra de arte sobretudo como "sintoma" de uma situação mais ampla e que se concentra nos aspectos genéticos e sociais que a engendram, os autores citados opunham um postura complementar, que exigia uma consideração prioritária da maneira como essa mesma obra se apresentava à percepção mais imediata e que levava em conta sobretudo o seu poder constantemente atual de transmitir o testemunho artístico através da expressão formal. É desnecessário dizer que a ênfase exclusiva sobre qualquer uma dessas posturas, em detrimento da outra, teria como resultado privar de antemão nossas análises de qualquer pretensão maior à integralidade.

Mesmo que tais textos devam ser referendados ao seu ambiente cultural específico, sendo em parte datados, ainda hoje permanece grande parte em aberto a questão de como integrar à historiográfia uma consideração adequada do que as obras diretamente comunicam através daquilo que Sedlmayr chamava suas "qualidades artísticas". Recentemente, Rudolf Arnheim, outro teórico da arte de origem alemã, reiteradamente abordou o problema, ainda que em um registro menos polêmico do que seus antecessores. Em um pequeno texto de 1970, intitulado "Sobre uma adoração", ele observa: "os historiadores e críticos podem dizer muitas coisas úteis sobre um quadro sem qualquer referência a ele como obra de arte. Podem analisar seu simbolismo, atribuir seus temas a origens filosóficas ou teológicas, e sua forma a modelos do passado; podem também usá-lo como um documento social, ou como a manifestação de uma atitude mental"'[4]. Arnheim lembra, contudo, que tudo isso pode se limitar a um entendimento da obra como um mero transmissor de informações factuais, e, fazendo referência ao texto de Sedlmayr acima citado, sustenta que a menos que o analista tenha apreendido intuitivamente a mensagem estética de um quadro, ele não pode esperar lidar intelectualmente com ela enquanto obra de arte. Para fazer isso, o teórico alemão conclui que "é preciso dar-se conta de forma sistemática, mas intuitiva, dos fatores de forma e cor que transmitem as forças visuais de direção, relação e expressão, pois estas forças proporcionam o principal acesso ao significado simbólico da arte"[5].

Como abaixo veremos, autores como Itten e Arnheim defendem que a maneira mais adequada de incrementar essa apreensão intuitiva das obras é praticar a arte, particularmente praticar o desenho. No que tange à análise da obras, tal prática é pensada não como um veículo de expressão subjetiva mas sim como um instrumento cognitivo e como uma estratégia expositiva. Igualmente, é possível observar que outros historiadores e teóricos 
freqüentemente lançaram mão em seus trabalhos dos próprios meios expressivos das obras que analizavam, tanto com a intenção de expor suas considerações quanto,- o que é mais significativo - como meio para desenvolvê-las. São exatttamente alguns exemplos dessa postura analítica que se vale da prática do desenho o que gostaríamos de apresentar no que segue.

2. Apesar de nossa introdução ter tratado apenas de teóricos de língua alemã, é possível perceber em outros ambientes culturais um apreço análogo pela prática do desenho relacionada à história da arte. $\mathrm{O}$ francês Germain Bazin é uma passagem de sua História da História da Arte, é um dos que partilha dessa concepção:

\begin{abstract}
Nada é mais difícil do que ver. Logo que nossa visão recebe a impressão de um objeto, se desencadeia um processo impulsionado pelos traços deixados na memória pelas percepções anteriores desse objeto ou daqueles análogos. É necessário portanto fazer o esforço de se desembaraçar dessa idéia e aplicar sua visão ao momento presente. Para tanto nada é mais útil para o historiador da arte do que desenhar, mesmo se esse desenho é desprovido de qualidade artística.[6]
\end{abstract}

Ainda segundo Bazin, foi somente através do desenho, processo que explicitava as suas "percepções visuais", que ele pode, por exemplo, se dar conta da lógica interna dos retábulos portugueses dos séculos XVI ao XVIII e propor-lhes uma morfologia.

Ouro historiador da arte francês que merece aqui ser lembrado é Henri Focillon, um dos primeiros a afirmar em seu país um primado do estudo das formas anterior à qualquer outro tipo consideração a respeito das obras de arte. Focillon se dedicou ao desenho, primeiro com a finalidade prática de ilustrar seus trabalhos, mas igualmente pelo gosto da criação pessoal. Os desenhos feitos com essa última intenção apresentam uma formidável variedade de técnicas e de fontes de inspiração: situados entre a recriação do estilo de um mestre e o desejo de auto-expressão, neles se confundem a homenagem e a ironia, a comunhão e o distanciamento, indissociáveis da sua figura pessoal, ao mesmo tempo historiador de arte e artista[7]. Embora tais obras não estejam ligadas diretamente a quaisquer considerações analíticas de Focillon, cremos que elas funcionavam, ao menos em parte, como um testemunho concreto do seu entendimento a respeito do caráter da obra de um mestre; nesse sentido, o que poderia ser mais convincente do que a realização de um trabalho "à la manière de" para provar que o estudioso compreendia o essencial dos procedimentos empregados por uma determinada personalidade artística?

Exemplos mais evidentes de análises que se valem da prática do desenho podem ser encontrados nos livros de Jurgis Baltrušaitis - não por acaso aluno de Focillon na Sorbonne durante os anos 1920 e muito influenciado pelas, como ele mesmo definia, "escolas alemãs", notadamente os teóricos da citada pura visibilidade. No período de seus estudos medievais, as análises morfológicas de Baltrušaitis se fundavam quase exclusivamente sobre desenhos lineares extremamente cuidados, ao mesmo tempo precisos e sintéticos, que revelam um evidente talento de desenhista. Nesse caso, é importante frisar, a descrição gráfica transcende à simples função de ilustração: ela representa como bem observou JeanFrançois Chevrier, "um verdadeiro instrumento de análise; ela lhe permite assimilar mentalmente, por imitação, os processos de invenção e os esquemas formais da arte da Idade Média. É pelo exercício de sua própria habilidade manual que ele pode expor, como tanta autoridade, as regras geométricas da escultura românica"'[8]. O próprio Baltrušaitis, no prefácio de sua obra Formátions, Deformátions, afirma a respeito da maneira como expôs o sistema morfológico e intelectual contido na ornamentação românica que "os desenhos 
acumulados à margem do texto constituem menos um complemento gráfico do que $a$ própria base de nosso desenvolvimento" [9].

Simultaneamente, a descrição gráfica que embasa as análises de Baltrušaitis é uma estratégia expositiva que lhe permite focar a atenção do leitor sobre aspectos específicos das obras abordadas. Dessa maneira, é através da confrontação direta de seus esquemas que ele procura reconstruir em um de seus primeiros livros - La stylistique ornamentale dans la sculpture romane, de 1931[10] -, a ordem, o pensamento e as reflexões qqque comandaram o desenvolvimento da arte ornamental românica. Em outro de seus textos - Art sumérien, Art roman, de 1934 -, é a partir de aproximações baseadas em critérios eminentemente formais que Baltrušaitis elabora suas considerações a respeito dos paralelismos encontrados entre a arte sumeriana e a arte européia dos séculos XI e XII: deixando em segundo plano as diferenças históricas, de função, de técnicas e de dimensão, ele se vale de uma apresentação depurada que expõe obras apartadas no tempo lado-a-lado, reduzindo-as à desenhos lineares e evidenciando suas semelhanças morfológicas, a partir das quais desenvolve hipóteses a respeito dos vínculos históricos por trás de tais convergências estilísticas.

3. Um dos mais ferrenhos defensores da prática do desenho relacionada à análise das obras de artes foi o já citado Johannes Itten: ainda insuficientemente conhecido nos meios artísticos brasileiros, Itten é não obstante uma figura bastante significativa da arte e da pedagogia artística das primeiras décadas do século passado, justamente na medida em que toda a sua atividade se encontra dentro de um campo de tensão entre racionalidade e irracionalidade, que foi comum a vários outros artistas do período. Suas próprias fontes de inspiração situam-se entre esses dois pólos: de um lado, temos Adolf Hölzel, professor de Itten em Stuttgart, o representante de uma abordagem da arte tendendo ao racional, como demonstram as suas pesquisas sobre as "bases da pintura", tema já reivindicado por Goethe; e, de outro lado, o referido Kandinsky do período de Munique, com a sua concepção da arte voltada para a mística e a espiritualidade, declarada já no seu tratado fundamental de 1912, Do espiritual na arte.

Para a compreensão de sua atuação como pintor e pedagogo, suas análises das obras de mestres antigos e modernos são essenciais: elas constituem o método de uma apreensão renovada da tradição, que se pretendia sensível àquilo que Kandinsky apelidava a "música interior" das obras de arte. Nessas análises, Itten não subordina a obra à linguagem, mas antes lança mão principalmente de meios artísticos. Mesmo antes do seu período como professor na Bauhaus, Itten definia o método e os objetivos das análises de mestres que eram um exercício rotineiro nas aulas por ele ministradas:

Nós queremos sentir o essencial de uma obra de arte. A fim de poder verificar se o sentimento é justo, ou seja apropriado à obra, nós devemos representar esse sentimento. Com a mão, o carvão, o papel. O essencial de meu curso consiste em representar esse sentimento: desenvolver a faculdade dos participantes de sentir a entidade e representá-la. [11]

E, em um pequeno artigo de 1927, significativamente intitulado "Como aprender a observar as obras de arte com exatidão?”, Itten ampliava suas considerações:

Nós podemos quotidianamente observar nos museus que "aqueles que saboreiam a arte" deslizam de quadro em quadro sem deles participar interiormente.

Onde está o erro? Nós não compreendemos as formas e as cores com todo nosso ser. Nós vemos de maneira demasiadamente superficial e captamos da arte apenas 


\begin{abstract}
a sua forma anedótica, nós só raramente vivemos as tensões e as relações que marcam a obra com o seu selo e transformam-na em uma obra de arte. O que podemos fazer?

Toda pessoa interessada em arte deveria ela mesma desenhar e pintar. Todo indivíduo interessado pode fazê-lo. [...] Basta que o professor dê algumas diretrizes, exercícios bem precisos para que os "menos dotados", os chamemos assim, se ponham a desenhar com uma mão segura. [12]
\end{abstract}

Um fator típico das análises de Itten e também daquelas realizadas por seus alunos na Bauhaus e posteriormente nos cursos independentes que ministrou, é que estas raramente colocam em questão a particularidade histórica das obras: para além das épocas e culturas, para além de toda descoberta filológica, Itten procura, como vimos, "sentir o essencial de uma obra de arte"; igualmente, através dessa obra particular, pensada em sua inerente singularidade, ele procura desvelar as supostas "leis da arte" que vigorariam de maneira atemporal e intercultural. É sintomático, portanto, que suas análises não constituam um corpus homogêneo, mas antes oscilem entre aqueles dois pólos da racionalidade e da irracionalidade acima citados.

Grosso modo, como propõe Rainer Wick, podemos dividir as análises de Itten e de seus alunos em dois grupos principais[13]. De um lado, temos o que poderíamos chamar análises de estrutura: estas repousam sobre uma abordagem eminentemente intelectual da obra de arte, cuja intenção principal é revelar os seus princípios fundamentais; usualmente, as análises pertencentes a esse grupo são considerações imanentes à obra abordada, e tratam de aspectos formais específicos como, por exemplo, a estrutura da composição, as proporções, a repartição de claro-escuro, a gênese do movimento, etc.; os desenhos dessas análises evidenciam, através da sua construção rigorosa, sobretudo as estruturas abstratas dissimuladas nas obras.

De outro lado temos um segundo grupo que Wick designa como análises de sentimento. Numerosos trabalhos de alunos de Itten ilustram o que este entendia por uma compreensão intuitiva do que caracteriza um quadro: neles, a apropriação da obra se efetua por uma relação de empatia, por uma espécie de comunhão do analista com a obra, que deveria se efetivar, em última análise, no próprio ato do desenho, no qual o gesto que gerava a forma presumivelmente incorporaria o caráter a ela subjacente; por isso, em tais análises não era necessário "dar as proporções exatas dos detalhes, mas sim traduzir o movimento, a vida, a expressão" [14]. Nessas análises onde a expressão é frequentemente intensificada, a contribuição da subjetividade do analista é evidente; todavia seria um erro considerá-las apenas como formas exteriores de um ato criador autônomo: para Itten, elas deveriam sempre representar um de diálogo entre sujeito e obra de arte, esta última considerada como algo que é dado de uma maneira objetiva.

Embora as análises de Itten devam ser entendidas principalmente em relação à sua pedagogia da arte, é claro que ele considerava que o acesso à natureza profunda das obras por essa via possibilitado não interessava apenas aos futuros artistas, mas sim a todos aqueles envolvidos com a arte, aí incluídos teóricos e historiadores. Não por acaso, certa feita Itten exprimiu o desejo de abrir um "curso para historiadores da arte": "eu desejaria tentar explicar a essa gente o que é importante, o que constitui a essência de uma obra de arte”[15], ele então diria, não sem um traço da sua veia de polemista.

4. Gostaríamos de considerar por fim alguns exemplos de análise presentes em obras de Rudolf Arnheim. Logo na introdução de seu mais conheciso livro, Arte e percep̧̧ão visual, cuja versão definitiva data de 1974, Arnheim frisa a importância do fazer artístico para aqueles 
interessados nos fenômenos da arte:

O mero contato com as obras-primas não é suficiente. Pessoas em demasia visitam museus e colecionam livros de arte sem ter acesso à mesma. A capacidade inata para entender através dos olhos está adormecida e deve ser despertada. E a melhor maneira é manusear lápis, pincéis, escalpelos e talvez câmaras.[16]

Um ortodoxo da teoria da Gestalt, como certa vez o definiu E. H. Gombrich, Arnheim freqüentemente adverte contra os perigos da análise "atomicista" da obra de arte e frisa a necessidade de uma consideração prioritária de sua totalidade. É por essa razão que ele costuma dar ênfase em seus trabalhos àquilo que designa como o "esqueleto estrutural" da obra. Um exemplo de análise que ilustra esse conceito é aquele da Criação do homem de Michelangelo, presente no capítulo final de Arte e percepsão visual, e que Arnheim faz acompanhar de um diagrama no qual o esqueleto estrutural da composição - que consiste basicamente no contraste existente entre as linhas principais que são induzidas pelos contornos externos de suas configurações - encontra-se destacado. Em obras como esta, sustenta Arnheim, o significado mais profundo é transmitido aos olhos imediatamente pelas próprias características perceptivas do seu esqueleto estrutural. lembrando como o próprio relato bíblico da criação de Adão foi modificado de modo a tornar a pintura mais compreensível e impressiva aos olhos, ele faz um verdadeiro curto-circuito entre conotação simbólica e dinâmica visual: O Criador, em vez de soprar uma alma viva ao corpo de argila - um motivo difícil
de se traduzir para uma configuração expressiva -, estende-se em direção ao braço
de Adão, como se uma centelha animadora, saltando da ponta de um dedo para a
ponta de outro, fosse transmitida do criador para a criatura. A ponte do braço liga
visualmente dois mundos separados: a compacidade autocontida do manto que
envolve Deus e o movimento para a frente é dado pela diagonal do corpo; e o
pedaço incompleto e plano da terra, cuja passividade é expressa no declive
posterior de seu contorno. Há passividade também na curva côncava sobre a qual
o corpo de Adão é moldado. Ele está deitado no chão e com possibilidade de
erguer-se parcialmente pelo poder atrativo do criador, que se aproxima. O desejo
e a capacidade potenciais para erguer-se e andar são indicados como um tema
secundário na perna esquerda que também serve de apoio para o braço de Adão,
impossibilitado de manter-se livremente como o braço de Deus, carregado de
energia.[17]

À princípio, esquemas como os de Arnheim ou Itten podem parecer demasiadamente simplificadores. Todavia, um fator que comprova sua relação com as obras aos quais se referem é a sua afinidade formal com uma categoria especial de desenhos de artistas, freqüentemente encontrada na gênese de uma obra de arte e que em língua francesa é denominada esquisse. $\mathrm{O}$ aspecto sintético do esquisse típico se deve à sua função essencial, a de fixar a idéia primeira de uma obra, que, segundo uma tradição firmemente estabelecida no Ocidente, é justamente a portadora do seu caráter essencial[18]. Essa comparação torna mais claro o fato de que tais diagramas não derivam diretamente de uma cópia do que percebemos ao olhar uma obra, mas são antes o resultado de um ato intencional de explicitação da dinâmica estrural subjacente ao objeto visual analisado; em uma de suas passagens, Arnheim adverte inclusive que tais diagramas só podem ser significativos se obedecerem à premissa de revelar a "criatura viva" à qual se referem[19]. Embora tais estruturas essenciais - que Arnheim sustenta, como vimos, serem as efetivas "portadoras de significado" de uma obra -, sejam diretamente perceptíveis, não podemos dizer que capacidade de conscientizá-las seja também inata; esta última capacidade deve ser 
exercitada, apurada, e é principalmente por esse motivo que ele prescreve a prática do desenho como a melhor maneira de desenvolvê-la.

Ainda segundo Arnheim, um mesmo esqueleto estrutural pode ser incorporado por uma grande variedade de formas e motivos. Análises que isolassem essas estruturas de base nas obras visuais poderiam servir como parâmetro para a formulação de uma categoria tipológica, preconizada já por Sedlmayr, que se basearia não na semelhança entre a aparência superficial das obras mas sim na identidade de seus temas dinâmicos subjacentes. Um exemplo de tal relação tipológica é apresentado pelo próprio Arnheim em seu livro $O$ pensamento Visual (1962), onde ele faz uma comparação entre duas obras bastante apartadas, consideradas as suas datas de realização ou mesmo suas características técnicas, um quadro de J. B. C. Corot, Mãe e criança na praia, e uma escultura do inglês Henri Moore, chamada Duas formas [20]. Destacando o esqueleto estrutural na base da pintura de Corot, que encarna o seu tema fundamental - nas palavras de Arnheim, "a criança, simétrica e vista de frente, repousa sobre o solo, à maneira de um pequeno monumento autônomo, enquanto a figura da mãe, curvada como uma onda, exprime, a 'proteção' e a 'solicitude"' -, e relacionando-o com a obra francamente mais abstrata de Moore, ele demonstra como os temas dinâmicos das duas obras são realmente similares. O teórico alemão não se preocupa, porém, em apresentar qualquer explicação para essa convergência; limitando-se a constatá-la, ele aponta como o tema encarnado pelo esqueleto estrutural de uma obra pode servir para ilustrar um tipo de acontecimento que, por ser genérico, transcende os próprios limites da arte: Arnheim conclui mesmo que o motivo pelo qual obras como estas nos tocam profundamente é o fato de nelas encontrarmos paralelos dinâmicos com situações humanas e naturais de significação essencial para nossa existência.

A guisa de considerações finais, é certamente necessário ressaltar que alguns pressupostos presentes no pensamento dos autores citados podem e devem ser problematizados. Entre eles gostaríamos de enumerar, sem a pretensão de sermos exaustivos, a) a crença em uma "essência" da obra de arte que seria diretamente acessível à percepção, crença esta que revela a vinculação de seus defensores a uma certa concepção "modernista" de arte, hoje em dia muito criticada; b) a idéia defendida por Arnheim, mas já presente em Itten, da existência de uma "capacidade inata para entender através dos olhos" os produtos artísticos e que estaria supostamente presente em todo ser humano; c) o caráter por vezes severamente reducionista das posturas analíticas aqui mostradas - que todavia não deve ser confundido, vale a pena ressaltar, com um mero e estrito formalismo, uma vez que essas análises não desconsideram as conotações simbólicas elementares das obras.

Ressalvas feitas, cremos não obstante que tais abordagens relacionadas à prática do desenho, aqui rapidamente apresentadas, são valiosas por diversos motivos: podem, como vimos, contribuir na identificação de famílias tipológicas e, conseqüentemente, nos trabalhos de atribuição e expertise, uma vez que são particularmente eficientes ao evidenciar recorrências estruturais relacionadas à configuração de um determinado conteúdo; podem também contribuir na ampliação do nosso entendimento de obras de arte individuais, através da conscientização e da representação de algumas de suas características fundamentais; cremos, por fim, que mesmo aqueles entre nós que não tenham a intenção de circunscrever suas considerações ao círculo por vezes árido da análise morfológica/estrutural, podem vir a se beneficiar do conhecimento proporcionado pelo processo de recriação que é a prática do desenho, uma forma de comunhão com a obra de arte que muito pode nos ensinar na difícil tarefa de ver. 
[1] SEDLMAYR, Hans. "Toward a rigorous study of art". In: WOOD, Christopher S. (org.). The Viena School reader: politics and art historical method in the 1930s. New York: Zone Books, 2000, p.138; uma versão em inglês do texto de Wertheimer ao qual se refere a passagem de Sedlmayr - Über Gestatlttheorie, de 1924 - pode ser encontrada no site http://www.gestalttheory.net/archive/wert1.html

[2] Diários, dezembro de 1917 - março de 1919. ITTEN, Johannes. L'etude des oeuvres d'art. Paris: Dessain et Tolra, 1990, p.41.

[3] A esse respeito ver KANDINSKY, Wassily. "Sobre a questão da forma" (1912). In: CHIPP, H. B. Teorias da arte moderna. São Paulo: Livraria Martins Fontes Edit. Ltda., 1993, p.154-170.

[4] ARNHEIM, Rudolf. "Sobre uma adoração". In: Intuição e intelecto na arte. São Paulo: Livraria Martins Fontes Edit. Ltda., 1989, p.3.

[5] ARNHEIM, Rudolf. Idem., p.4.

[6] BAZIN, Germain. Histoire de l'bistoire de l'art. Paris: Albin Michel, 1986, p.176.

[7] Ver os desenhos reproduzidos no anexo I de KUBLER, George [et alli]. Relire Focillon. Paris: École Nationale Supérieure des Beaux-Arts, 1998.

[8] CHEVRIER, Jean-François. Portrait de Jurgis Baltrušaitis. Paris: Flamarion, p.102.

[9] BALTRUŠAITIS, Jurgis. Formations, déformations. La stylistique ornamentale dans la sculpture romane. Paris: Flammarion, 1986, p.8.

[10] Essa obra, cujo ano de edição original significativamente é o mesmo do célebre livro de Focillon, L'art des sculpteurs romans -, foi reeditada com uma redação bastante modificada em 1986, no acima citado Formations, déformations.

[11] Diário, fevereiro de 1919. ITTEN, Johannes. Op. cit., p.11.

[12] ITTEN, Johannes. Idem., p.121.

[13] $\mathrm{Na}$ verdade, Wick propõe três categorias para classificar as obras de Itten; à última e mais restrita, a qual aqui não discutiremos, pertenceriam as chamadas "análises de mestres antigos", reunidas pelo pintor na sua obra Utopia, publicada em Weimar em 1921 e que constituiriam, segundo Wick, uma espécie de "contemplação mística com meios picturais específicos" (ver WICK, Rainer. "De tradition à l’innovation. Au sujet des analyses des oeuvres d'art d'Itten”. In: ITTEN, Johannes. Idem., pp.11-12 e pp.46 sg.).

[14] ITTEN, Johannes. Idem., p.124.

[15] Diários, dezembro de 1917 - marco de 1919. ITTEN, Johannes. Idem., p.41.

[16] ARNHEIM, Rudolf. Arte e percep̧cão visual - uma psicologia da visão criativa. São Paulo: Livraria Pioneira Editora, 1991, xiii.

[17] ARNHEIM, Rudolf. Arte e percep̧ão visual..., pp.451-452.

[18] Arnheim constatou que isso era realmente verdade, por exemplo, no caso da Guernica de Picasso, obra a qual dedicou um livro: "o primeiro esboço de Picasso para a Guernica contém muito da forma básica final, e sem dúvida o pequeno esboço sobre uma folha de papel azul se aproxima mais da composição do mural do que tudo que o pintor expôs antes de começar a tela definitiva" (ARNHEIM, Rudolf. La Guernica de Picasso: genesis de una pintura. Barcelona:Editorial Gustavo Gili, 1976, p.44).

[19] ARNHEIM, Rudolf. La pensée visuelle. Paris : Flammarion, 1976, p.64.

[20] [20] ARNHEIM, Rudolf. La pensée visuelle..., p.284. 